\title{
LENDO MURILO MENDES NA SALA DE AULA, COM ANTONIO CANDIDO \\ READING MURILO MENDES NA SALA DE AULA, UITH ANTONIO CANDIDO
}

\author{
ÉVERTON Barbosa CoRREIA'
}

RESUMO: Com a primeira publicação em 1985, Na sala de aula é um volume que reúne uma coleção de seis ensaios sobre momentos distintos do desenvolvimento da poesia luso-brasileira sob a escrita de Antonio Candido. Quando o crítico se volta para a apreciação da poesia algo de seus escritos anteriores repercute no seu desempenho, considerando que teoria e historiografia literárias são modalidades discursivas que constituem o seu ofício. Tomando o último capítulo do volume, no qual a obra de Murilo Mendes é apreciada, intenta-se demonstrar a estratégia de leitura utilizada pelo crítico em larga escala, ainda que restrita à ilustração de um único poema.

PALAVRAS-CHAVE: crítica literária, leitura, poesia.

ABSTRACT: Published first in 1985, Na sala de aula is a volume which brings together a collection of six essays about different moments of Luso-Brazilian poetry development in the writing of Antonio Candido. When the critic turns to poetry appreciation something from his previous writings reflects on his performance, considering that literary theory and historiography can be made discursive modalities that constitute his work. Taking the last chapter of volume, in which the work of Murilo Mendes is addressed, it is intended to demonstrate the reading strategy used by critic on a large scale, even if restricted to the illustration of a single poem.

KEYWORDS: literary criticism, reading, poetry.

1 Doutor em Teoria Literária e Literatura Comparada pela Universidade de São Paulo e Professor Adjunto - Departamento CULT e do Programa de Pós-graduação em Letras - Instituto de Letras UERJ - Universidade do Estado do Rio de Janeiro, Campus Maracanã. 
Mais do que sugestivo, Na sala de aula é um título indicativo do lugar onde acontece certa experiência simultaneamente didática e histórica, que, quando associada ao nome do seu autor, soa como algo instigante por remeter a conteúdo literário, sobre o qual o volume se propõe a refletir. Delineado o horizonte de exploração, vem a ser curioso que não esteja explícito em seu conteúdo nada que remeta a dinâmicas de leitura ou à assimilação de tecnologias a serem incorporadas por práticas de ensino para o melhor desempenho do professor ou do rendimento do aluno. Tampouco existe ali qualquer direcionamento para a relação entre professor e aluno que mereça atenção especial, quando contingenciados no processo de aprendizagem, pautado pela apreciação literária. Ao invés, sugere-se a existência de uma tradição literária constituída, passível de entendimento, a considerar o acúmulo de leitura existente sobre um painel histórico que vem a definir, circunstancialmente, a convenção linguística e literária em vigor. Daí a disponibilização de uma coleção variada de artigos curtos que abordam poemas diversos de poetas luso-brasileiros, a que se deve reputar seu subtítulo: caderno de análise literária. Embora só tenha adquirido forma de publicação trinta anos depois, em 1985, o texto reúne anotações de fins dos anos 1950 , conforme o crítico mesmo adverte no prefácio do volume, junto a orientações de leitura, como se segue.

Este caderno contém seis análises de poemas, que procuram sugerir ao professor e ao estudante maneiras possíveis de trabalhar o texto, partindo da noção de que cada um requer tratamento adequado à sua natureza, embora com base em pressupostos teóricos comuns. Um desses pressupostos é que os significados são complexos e oscilantes. Outro, que o texto é uma espécie de fórmula, onde o autor combina consciente e inconscientemente elementos de vários tipos. (CANDIDO, 2017, p. 9)

Ora, sendo a compreensão do que venha a ser o texto poemático algo variável, de acordo com a intenção e a disposição do autor, sua interpretação haverá de resvalar numa significação igualmente oscilante, cuja complexidade será aferida e sedimentada por cada leitor situado histórica e geograficamente. $\mathrm{O}$ raciocínio bastante generoso, porquanto parece razoável, tem como horizonte a experiência de leitura mesma, cujos limites se verificam no cotidiano de quem lida com tal prática, uma vez que é bastante difícil fixar o sentido de um texto, 
quando concebido como parte de uma coletividade, para a qual convêm acionar o lastro de leituras anteriores, que se oferecem como outro limite prático e objetivo. Como lidar com o texto que já foi lido por outros, em temporalidades distintas e, por conseguinte, com repertório e interesses diversos? Qualquer que seja a resposta, não será alcançada sem ultrapassar o limite da curiosidade que, eventualmente, é motivada pelos agentes envolvidos, não raro um professor diante de alunos, que parece ser o alvo do escrito, conforme assinala ainda no mesmo prefácio.

Tenho consciência de que o tipo de trabalho apresentado aqui se ajusta melhor à sala de aula, onde tudo ganha mais clareza devido aos recursos do gesto e da palavra falada, com o auxílio do fiel quadro-negro e seu giz de cor. Reduzidas à escrita, as análises perdem força; mas creio que ainda assim podem valer como registro dum tipo de ensino, e eventual ponto de apoio a professores e estudantes. Isso é dito para o leitor se capacitar de que este caderno não é um conjunto de ensaios, mas um instrumento de trabalho, contendo texto analíticos dependentes, isto é, que não foram lidos por si mesmos, mas em correlação estreita com os poemas. Por isso é preciso não perder de vista os poemas, que podem ser consultados a cada alusão. (CANDIDO, 2017, p. 10)

O fiel quadro-negro e o giz de cor trazem uma marca do tempo, que pode ser atualizada pelos pinceis atômicos e pelo quadro branco, sem grande prejuízo. Difícil é manter nos dias de hoje o entendimento de que a aprendizagem se torna mais sofisticada com o gesto e com a palavra falada, a considerar o arsenal de instrumentos digitais e audiovisuais, que intentam substituir, quando não suplantar, o desempenho e o papel do professor diante do aluno. Eis aí outra marca do tempo, que sequer foi cogitada antes, por parecer segura e estável a relação entre o professor e o aluno, que não deve se reduzir à escrita, que por si só fragiliza a análise. Outra particularidade que não poderia ser concebida então é a de imaginar que o volume não devesse ser considerado como um conjunto de ensaios, como se o professor pudesse dispor de ocasião para apreciar o volume na íntegra, já que lhe é reputado um valor instrumental. Qual não é a surpresa ao constatarmos que a prática pedagógica, consensualmente exercitada nos cursos de Letras do país, se pauta pelo seccionamento de conteúdos, abordagens e instrumentos, seguindo a visão de que a diversidade é invariavel- 
mente um valor. Diante da constatação, não existe outra possibilidade senão a de considerar o volume como um conjunto de ensaios cujo manuseio irá depender sempre da conveniência curricular vigente ou dos interesses em pauta, um tanto à revelia do próprio autor. Talvez ele imaginasse que o seu livro pudesse ser tomado como um manual de leitura literária, em substituição analítica aos antigos florilégios, mas isso constitui tão só outra marca do tempo, quando a coleção de poemas por si só justificava sua abordagem perante um público ilustrado ou em formação.

Mais curioso ainda é notar que a tal análise literária aventada no subtítulo do livro se dê ali exclusivamente por meio da poesia, levantando uma questão de método para seu leitor: tratando-se de literatura em geral, por que a eleição da poesia como o gênero para análise? Não fosse Antonio Candido o crítico que desenvolveu inúmeras análises de romances - a começar pela célebre "Dialética da malandragem" (CANDIDO, 2015, p. 16-47) - o subtítulo do seu livro despertaria alguma cisma, haja vista que a literatura é mais do que a poesia e a poesia não basta para explicar de todo o que é literatura, ainda que ilustrativamente, o que mantém tesa a pergunta: por que a poesia? Por que logo em sala de aula? Se cotejarmos os Parâmetros Curriculares Nacionais (PCNs) vigentes, a poesia parece poder estar em qualquer lugar, que não seja a sala de aula. Diante do confronto de ambas as perspectivas, ou o crítico parece não se adequar às reivindicações dos dias atuais ou, a considerar os PCNs, a sala de aula não se oferece mais como lugar propício ou mesmo cabível para a apreciação do texto poemático e menos ainda do gênero lírico.

Assim colocado de chofre, o problema de método nos conduz a uma constatação incontornável: o esvaziamento e a rarefação do estudo da poesia nos cursos de Letras do país afora, nos quais o templo das musas simula uma referência obsoleta e em franco desuso, a despeito do mandamento teórico de não existir hierarquia entre os gêneros, sem repercussão na realidade concreta dos estudos literários, para a qual a poesia faz figura de exceção devido à sua hipotética obsolescência, transferida às vezes para a letra de música e às vezes para a reivindicação social presente na matéria abordada. Mais curioso é notar que a poesia é de domínio exclusivo das letras e não sobrevive em áreas afins, como outras modalidades literárias, a exemplo da dramaturgia ou do ensaio. Mesmo sem constar explicitamente na Póetica aristotélica como gênero autônomo - o que coube à tragédia e à epopeia -, a poesia, tal como a entendemos hoje, 
reclama princípios formais reconhecíveis, mesmo quando não é portadora de formas fixas - a exemplo do soneto, que demanda um instrumental de leitura específico. De outro modo, a experiência de leitura se restringe a aferir o grau de semelhança ou de diferença da nossa experiência social em face de outras, quando a forma é descartada, o que nunca acontece com Antonio Candido, se investido da condição de leitor de objetos literários circunstanciados.

O caso de Antonio Candido se mostra especialmente notável porque sua formação passou pelo direito e pelas ciências sociais, o que tornaria previsível e até legítimo que sua apreciação literária se voltasse para aspectos contextuais da abordagem do fenômeno artístico vazado em linguagem verbal, mas não será esta a tonalidade de seu discurso, fortemente amparado pela forma literária. Isso pode ser percebido quando analisa a personagem Leonardo do Memórias de um sargento de milícias para chegar à sua conceituação da "Dialética da malandragem" - para ficar no mesmo exemplo -, e mais ainda quando se volta para a apreciação de objeto literário grafado em versos. Embora aquele seu ensaio crítico tenha um alcance que ultrapassa a fronteira dos estudos literários, estendendo-se em perspectiva histórica ou sociológica do Brasil, é antes de tudo um ato de leitura circunstanciado, que considera leituras anteriores do romance oitocentista - tanto de José Verissimo quanto de Mário de Andrade. A partir de tais posicionamentos, ele se propõe a desenvolver uma apreciação abalizada por um princípio filosófico que é a dialética aplicada ao pícaro, para incidir sobre um elemento formal que é a personagem, o qual, por sua vez, se enreda e repercute nos demais elementos constitutivos da tessitura romanesca para, somente então, oferecer nova possibilidade de entendimento da obra, sob a designação da "malandragem" e suas derivações, só que agora não mais atrelado unicamente nas leituras anteriores, o que permite uma compreensão histórica e perspectivada da leitura. Assim, seu exercício crítico se constitui efetivamente, porque considera a historiografia em que se insere a obra, pautada pelo acúmulo de sua leitura, e se vale de um princípio teórico que incide nuclearmente sobre a compreensão da obra. Com isso, produz um entrelaçamento da crítica com a historiografia e a teoria, para dispor de um tipo de conhecimento bem específico, só possível como decorrente da leitura da obra literária. O comentário interessa para deixar claro que o mesmo procedimento aplicado à sua crítica mais conhecida é extensivo a outros atos de leitura seus, notadamente quando se volta para a poesia. 
É evidente que a repetição do procedimento traduzido da prosa para a poesia não poderia sugerir algo mecânico, uma vez que cada objeto literário circunstanciado no tempo vai demandar um tipo de apreciação diferenciada - tal como advertira no prefácio por meio da sua compreensão de texto -, sem permitir jamais que um soneto de Vinícius de Morais pudesse ser lido como um de Luís Vaz de Camões, por exemplo. Se o raciocínio vale para os exímios sonetistas, vale muito mais quando acionamos pressupostos formais diversos entre si, não só no tempo e no espaço, mas na elaboração expressional. Eis aí a razão pela qual, ao longo do seu "Caderno de análise literária", Antonio Candido em momento algum cogitou a leitura de Santa Rita Durão como se fosse Alberto de Oliveira ou de Tomás Antônio Gonzaga como se fosse Álvares de Azevedo e a isso se deve a modulação de sua estratégia de leitura que vai variar sempre de acordo com o objeto apreciado, ainda que possamos descrevê-lo bem genericamente sob a divisão nem sempre simétrica entre comentário, análise e interpretação (CANDIDO, 2006, p. 27-36).

Assim como já foi dito que teoria, história e crítica se cruzam no exercício de leitura de Antonio Candido, quando nos voltamos para seus próprios escritos, é fácil perceber a interferência de outras modalidades discursivas suas na compreensão e no desenvolvimento do ato analítico com vistas à interpretação, aplicando-se simultânea e exemplarmente ao compêndio $A$ formação da literatura brasileira (1959) como pressuposto historiográfico, bem como a $O$ estudo analítico do poema (1987) para exercer a leitura de poesia. De uma maneira ou de outra, sua apreciação do objeto literário se processa contextualmente tanto em consideração aos leitores que o antecederam - críticos que apreciaram o objeto literário em pauta - quanto aos que o sucederão - estudantes e professores que haverão de se ocupar daquele mesmo objeto literário. Com isso, importa afirmar a relação viva e dinâmica entre autor, obra e público como não apenas uma idiossincrasia crítica particular, mas sim como instâncias de visualização do fenômeno literário, tornado bem simbólico, circunstanciadamente.

Tal compreensão está presente no volume $\mathrm{Na}$ sala de aula incisivamente, porquanto atravessa um arco temporal que abrange a produção literária desde quando os autores ainda se expressavam como representantes da América portuguesa, a que serviam e com a qual se identificavam, até a modernidade brasileira do século XX. Daí sucede que a relação entre comentário, análise e interpretação vai variar de acordo com o objeto em foco, ocasionalmente prio- 
rizando um aspecto de leituraou outro. De maneira que o comentário devotado a um canto de $O$ caramuru - tal como ocorre no capítulo "Movimento e parada" terá uma duração bem maior do que a explicação dos porquês da leitura de um poema de A lira dos vinte anos - constante no capítulo "Cavalgada ambígua". A distância histórica como que solicita maior consideração contextual, ao passo que uma obra mais próxima no devir temporal nos parece mais palatável, dispensando-nos de explicações extratextuais exaustivas, pois seu entendimento parece ser imediatamente inteligível quando depurado da forma, sem maiores comprometimentos. Por outro lado, quanto maior a imbricação formal dos elementos constitutivos do poema, maior a consideração analítica a ser feita, o que ocorre com as apreciações das obras de Manuel Bandeira no capítulo intitulado "Carrossel" e de Murilo Mendes, no capítulo de encerramento do volume sob o título de "O pastor pianista/ o pianista pastor".

Observando aquele caderno de análise literária como um todo, dispomos do seguinte desenho: seis artigos aos quais correspondem seis análises voltados para seis poetas distintos, historicamente distribuídos assim: um barroco, um neoclássico, um romântico, um parnasiano e dois modernos. Ainda que possamos reputar alguma identidade aos poetas modernos ou aos poetas coloniais - barroco e neoclássico -, não é isso que ocorre por ocasião das análises e, por extensão, também não há coincidências ou similitudes nas interpretações a que o crítico chega, como se os períodos assegurassem a efetividade da leitura. Ao invés, todo o seu movimento crítico se guia pela consideração absolutamente individual de cada autor e de cada obra autoral. Por isso, não é certo que sua leitura do "Rondó dos cavalinhos" coligido no volume Estrela da manhã de Manuel Bandeira - constante no capítulo "Carrossel" - seja aplicável a todo o restante da obra poeta pernambucano, ainda que a hipótese seja sedutora. Ocorre que as circunstâncias de pronunciamento são tão determinantes do entendimento do fenômeno literário que aquilo que Bandeira escreveu nos idos de 1936 não pode ser imediatamente transferível para o que ele viria a publicar quase trinta anos depois em Opus 10 e, menos ainda, o que tinha escrito vinte anos antes, quando da publicação de $A$ cinza das horas. Se o balanço do raciocínio não vale como paradigma autoral, vale como sintagma de sua leitura: semanticamente a leitura não é transferível, mas a reprodução da estratégia de apreciação é perfeitamente aceitável para aplicar a outros poemas de outros livros seus. 
O comentário assim em diagonal deve servir ao menos para ilustrar a compreensão do crítico por meio de cada obra particular que produz em face da respectiva recepção, não como um todo acabado, mas como um acúmulo de experiência passível de registro, que se faz histórico. Por outra, também intenta mostrar como os bens simbólicos, mesmo os mais recuados no tempo, podem ser compreendidos no seu contexto de pronunciamento, ainda que resultantes de ambientes inóspitos e até hostis à circulação de informações, como foi o da América portuguesa, que não permitia a visualização nítida de um "sistema literário" socialmente sedimentado com casas editoriais e público consumidor definido. Com isso, era previsível o deslocamento da compreensão da obra para especulações centradas na figura autoral e sua inserção na sociedade a que teve acesso, o que deve invariavelmente ser evitado como elemento de valoração da obra. Diante de tais limitações analíticas, outra haverá de ser a compreensão de "sistema literário" quando aplicado à época colonial, a considerar o que então se oferecia como obra e como público leitor. Também por isso, aquelas produções não poderiam ser contabilizadas pela mesma bitola das produções burguesas - fossem românticas ou realistas - para quem pretendia mostrar o processo de formação cultural por meio da produção e circulação da literatura, e não pela matéria que, eventualmente, carregasse. Esta é a limitação básica das produções coloniais com as quais seus leitores tiveram que lidar justamente porque Ihes faltavam os fios que ligassem o produto social que é o livro, circunstancialmente determinado, aos seus consumidores, necessariamente tributários de casas editoriais, clubes de leituras ou academias, o que nunca foi fácil divisar e tampouco descrever na América lusitana, até porque não se aplicava com precisão nem mesmo ao padre Antonio Vieira e menos ainda a Gregório de Matos e Guerra.

Sob tal prisma, o "sistema literário" se volta prioritariamente para a articulação social do autor, da obra e do público tal como estão prefigurados em decorrência do mercantilismo, a que tivemos acesso sob o modo de produção capitalista periférico - que no Brasil se confunde com o regime escravista -, o que não era possível quando as matrizes mercantis ainda estavam se gestando e adquirindo forma social, ainda não definida na época de nossa colonização. Portanto, se Durão e Gonzaga comparecem na formulação historiográfica de Antonio Candido constante no livro Na sala de aula, respectivamente, nos capítulos "Movimento e parada" e "Uma aldeia falsa", é mais como lastro de uma tradição 
literária que se constituiu a posteriori como brasileira, do que propriamente pela hipótese de uma brasilidade anterior à Independência.

Desbastadas as arestas que envolvem o volume $\mathrm{Na}$ sala de aula de Antonio Candido, passemos à análise de seu último capítulo, que baliza um ponto de chegada ali. O objeto de apreciação do capítulo é a poesia de Murilo Mendes, formalizada no poema "O pastor pianista" do livro As metamorfoses (1944), que desperta mais interesse pelo seu caráter enigmático e sofisticado, do que pela representatividade social circunstancialmente visível. Já no início do texto, Antonio Candido avisa que o leitor deve ter a postura aberta quando se depara com um objeto inusitado ou rarefeito aos olhos da tradição. Tal circunstância de leitura não deve coibir o seu desenvolvimento, procurando encontrar instrumentos que lhe sirvam de amparo. Tal advertência de leitura deve servir de estímulo ao leitor quando se encontra diante de um limite concreto, sem que se deixe intimidar, para que se sinta impelido a buscar instrumentos que possam lhe dar algum suporte discursivo. Não podendo se valer da rima ou da métrica como estratégias de apreciação, ele projeta seu olhar para a disposição das palavras, a pretexto de lhes consignar uma forma, passível de reconhecimento, decifração e descoberta, que devem ser sintetizadas pela interpretação a que precisa chegar. Deixando claro, desde o primeiro momento, que não podemos nos lançar prontamente no plano do significado, como se aí residisse a efetividade discursiva. Se assim fosse, o texto dispensaria sua organização formal, que é justamente o que Ihe confere fisionomia artística, sem a qual jamais o poema atingiria o público sem o efeito estético que proporciona.

Durante os capítulos anteriores, o crítico se empenhara em demonstrar como os fatos estéticos são circunstancialmente determinados e como devemos apreciar a individualidade autoral diante da compreensão que lhe foi atribuída pelo acúmulo de sua leitura. Há também um trabalho com a ideia de como podemos ampliar tal compreensão, que se atualiza na sua historicidade a cada ato crítico, o que se aplica a uma forma fixa como o rondó, ou ainda, a um canto de uma grande composição lírica, como foi o caso da lira 88 de Marília de Dirceu. 0 recorte interessa, pois, como etapa do método para dimensionar o trajeto autoral que precisa ser reiterado, no contexto de pronunciamento de cada autor que constitui uma tradição literária e prefigura uma tradição de leitura. Segundo a perspectiva acionada, tradição literária e tradição de leitura se atualizariam a cada ato crítico, para se constituírem como bens simbólicos de uma deter- 
minada coletividade, ocasionalmente moderna e brasileira. No caso de Murilo Mendes, todas as referências estão dadas, porque ele navega com segurança na tradição clássica, bem como nas expressões modernas, que manipula tão bem a ponto de se destacar entre os próprios surrealistas, que ofereciam um conceito para encobrir sua poesia, sem a incorporar de todo. Impossível de ser apreendido pela designação surrealista, outro deveria ser o ancoradouro que lhe servisse de apoio para dizer qual o envolvimento material de sua produção com a realidade circundante e como tal realidade repercutiria na radiografia expressional do poeta.

De antemão, cumpre lembrar que se trata de uma poesia pautada pela ampliação deformadora da realidade, o que, aos olhos do crítico, já produziu efeitos muito significativos para nosso desenvolvimento histórico. A pretexto de ilustrar o argumento, toma os versos de Gregório de Matos e Guerra para demonstrar que aquilo que Murilo Mendes empreende na poesia já era de conhecimento público, não só pela via do autor abordado, mas pelo que pode ser rastreado numa tradição mais remota e que se quer brasileira. Portanto, implica reconhecer uma tradição poética luso-brasileira, não raro tomada como melodiosa ou apaziguadora, o que é logo contradito quando nos deparamos com autores como Bocage, Gregório de Matos, Cesário Verde ou Augusto dos Anjos. É, portanto, neste outro veio da mesma tradição em que se insere o Murilo Mendes ali recortado, reconhecido menos pelo consenso que desperta, do que pela impressão que causa.

Tudo isso vem a calhar para dimensionar a escolha de crítica de Antonio Candido e o perfil de leitor que ele deseja formar: menos colado na linearidade histórica e mais capaz de discernir por si próprio o que confere valor estético a uma obra, notadamente se tomarmos como obra o poema. Considerado autonomamente, o poema "O pastor pianista" viria a ser apreciado naquela circunstância em função do volume que o enfeixa como um conglomerado de partes com as quais dialoga temática e formalmente. A pretexto de ilustrar o diálogo, o crítico rastreia ao longo do volume outros poemas em que aparece a palavra "ideia", uma vez que a locução "rosas migradoras" constante naquele poema soa um tanto enigmática. E vai encontrar similitudes, a exemplo de "ideias migradoras" ou "ideias rosas", fazendo com que a contiguidade vocabular confira certo sabor material à "ideia" tal como comparece nos poemas de Murilo Mendes. A contiguidade dos termos vale menos pela sofisticação do procedimento em si, 
do que pela conotação particular que adquire quando limitada com um objeto particular que o representa, seja "rosa" ou "migradora". Ora, uma ideia migradora ou rosa pode ser qualquer coisa que se aproxime de uma ideia, sem o ser de fato, já que ideias não tem cor e tampouco migram por si, senão por quem as manipula. Tal compreensão de linguagem é o que vem animar sua compreensão da obra muriliana, cuja feição se consolida tanto mais, quanto maior for sua consideração no contexto de pronunciamento específico, o que nos leva de pronto à seleção lexical.

Não estranha, a partir disso, que a bola da vez teórica eleita pelo crítico tenha sido justamente o brilhante ensaio "Linguística e poética" de Roman Jakobson em período de refrega das ondas formalista, estruturalista e funcionalista que assolaram as universidades brasileiras e que tinha figura proa no nome do teórico russo. Ao incorporar aquele postulado para analisar o poema de Murilo Mendes, o crítico literário atualiza o instrumental de leitura de poesia para além da descrição historiográfica e coloca a expressão autoral em perspectiva para além de seu pronunciamento, supondo uma possível universalização do poeta e do instrumental de leitura que se cruzam, por meio das respectivas particularidades. Sem reduzir a leitura do poema às famigeradas "funções da linguagem", o contingenciamento da poesia muriliana ao instrumental linguístico visa a justa valorização do efeito poético decorrente da sobreposição dos planos da seleção e da combinação, ou ainda, do eixo sintagmático sobre o paradigmático, como se queira. Do modo como foram incorporadas por Antonio Candido, as categorias ultrapassam a aplicação ao contexto brasileiro sob a ilustração de um poeta cosmopolita. Muito mais do que isso, a seleção entendida como constitutiva de meio expressional elege e exclui possibilidades, para produzir uma combinação que é, a um só tempo, eletiva e exclusiva, o que é absolutamente compativel com os princípios que devem animar o fazer poético.

Cumpre assinalar reiteradamente que sendo um construto teórico absolutamente exterior ao contexto brasileiro, os pressupostos de Roman Jakobson poderiam funcionar como fórceps que extrai a interpretação da obra descolada de seu contexto de pronunciamento, mas não é exatamente isso que acontece diante de Murilo Mendes, quando lido por Antonio Candido. Em parte, pela adequação do instrumento leitura utilizado para a apreciação do objeto a que se Ihe aplica e, em parte, porque considera o objeto literário nos termos de sua constituição linguística singular, que vem adquirir representação social e, 
por conseguinte, pública. Mesmo sendo Murilo Mendes um autor escancaradamente cosmopolita, a impressão que temos ao sair do texto de Antonio Candido é que o poeta ficou mais brasileiro, mesmo falando de pianos que gritam e são apascentados. Não havendo nada de particularmente nacional na matéria abordada, a singeleza do tratamento que lhe é dispendido confere certa atmosfera singular, que só seria devidamente inteligível se considerados os modelos de representação nacionais acionados por um leitor ciente de tais disposições autorais e simbólicas. Quanto mais não seja uma apreciação exclusivamente individual, uma vez que Murilo Mendes aparece ali como ponto de chegada, é como uma voz particularizada em contexto de pronunciamento preciso que ele se nos oferece.

Surge, então, diante de nós a imagem de um Murilo Mendes imenso, nem tão católico quanto surrealista, mas brasileiro até seu limite possível, quando a expressão perde a força dos referentes que não indicam mais a realidade tangível, mas inscreve antes uma particularidade estilística radicada de modo tão imperativo nos significantes verbais que descarta qualquer suspeita acerca de sua inscrição histórica ou geográfica, o que só nos leva a uma consideração muito amistosa do Brasil com que nos defrontamos naquela obra, porque absolutamente impalpável. Não se trata de um Brasil aprazível ou mesmo aceitável, mas aberrante e descomunal como deve ser um gigante pela sua própria natureza, ao qual é sempre difícil divisar onde começa a realidade, a não ser que estejamos dispostos a começar por uma suprarrealidade, ou ainda, uma sobrerrealidade que vem a ser constitutiva da nossa experiência cotidiana como tem sido e ainda haverá de ser por um bom tempo, conforme o crítico também corrobora.

A planície deserta, os pianos gritando ao luar, as sombras sem pássaros, as rosas andejas são isso mesmo, permanecem tais, vinculados por nexos arbitrários da visão surreal. O que há neles de abstração foi reduzido à dimensão concreta, como as 'ideias rosas'. E eles formam o quadro para o poeta fazer, na segunda parte, a sua reflexão, que entre em contraste com a fantasmagoria da primeira, mediadas antes pelo pastor. Entre os pianos e os homens talvez haja uma correlação mais funda, que unificaria de maneira dialética a parte impertinente e a pertinente, sugerindo que, em última instância, o efeito poético é devido à 
tensão entre o possível rebanho sonoro dos pianos e a luta do homem para se exprimir. (CANDIDO, 2017, p. 144-145)

A falta de receio em colocar a produção de Murilo Mendes noutra estratosfera é justamente o que dignifica a expressão poética, perfeitamente capaz de sobreviver sem mediação de relativismos históricos ou nacionalistas, cujos expedientes analíticos carregados de "poréns" e "senões", em vez de iluminar a compreensão do fenômeno literário, circunstanciado estética e linguisticamente, obscurece os mecanismos de representação e conduz a interpretação para o significado de superfície inscrito na referência. Sem antecipar a piedade a si mesmo ou a compaixão nacional como instauradores da representação literária praticada em língua portuguesa por rebentos do chão brasileiro, a expressão literária ganha mais por se isentar de dar satisfações sobre os critérios a seguir, menos do que pelo desempenho alcançado, que não fica devendo nada a nenhuma tradição exterior, que não possa ser reconhecida como própria ou simplesmente incorporada à brasileira.

Tudo isso ganha relevo se consideramos que na expressão muriliana, esquiva a sabiás e rouxinóis ou palmeiras e araucárias, nada concorre para a revalidação de referentes reconhecíveis ou significantes tornados compulsivamente pátrios, mesmo se nos referirmos ao seu livro de poesia História do Brasil (1932). Talvez por isso a poesia brasileira tenha atingido a excelência compatível a qualquer outra tradição literária, o que acontece com Murilo Mendes e com mais uma dúzia de poetas brasileiros. Não exatamente porque seu discurso seja palatável ou passível de fácil instrumentalização política, histórica, religiosoa ou sociológica, mas muito mais porque foi possível ver como um sujeito em situação definida fez com que a linguagem fosse até onde ela não podia ir por conta própria, sem o esforço de se expandir até o sem-sentido em que a poesia permite renovar-se e se ampliar. Tal como Antonio Candido nos fez ver e dá a ver por meio de um poema hermético, talvez fútil ou indecifrável, quem sabe até mesmo banal, conforme a composição que se segue e deu ensejo a toda reflexão aqui esboçada, que no seu texto é ponto de partida, porque está transcrita antes de qualquer elucubração. 


\section{O pastor pianista}

Soltaram os pianos na planície deserta

Onde as sombras dos pássaros vem beber.

Eu sou o pastor pianista.

Vejo ao longe com alegria meus pianos

Recortarem os vultos monumentais

Contra a lua.

Acompanhado pelas rosas migradoras

Apascento os pianos que gritam

E transmitem o antigo clamor do homem

Que reclamando a contemplação

Sonha e provoca a harmonia.

Trabalha mesmo à força,

E pelo vento nas folhagens

Pelos planetas, pelo andar das mulheres,

Pelo amor e seus contrastes,

Comunica-se com os deuses. (MENDES, 1994, p. 343)

Quando nos deparamos concretamente diante da composição lírica transcrita acima, parece um tanto enigmático o resultado da leitura a que Antonio Candido chegou, fazendo-nos acompanhar seu percurso, um pouco consternados. Sua habilidade, portanto, ultrapassa em muito a utilização imprevista ou licenciosa de um instrumental de leitura, que nos faz parecer inusitado o seu raciocínio ou o seu aproveitamento do objeto literário em pauta. Não é pela virtuose do raciocínio que o crítico nos apanha e nos conduz até o final do seu livro, capítulo a capítulo, sendo o último talvez o mais pedregulhoso, como se viu. Mais do que a exibição de sua habilidade de leitor, o desempenho crítico ganha relevo e salta aos olhos de outros leitores, pela sua capacidade fenomenal de convencimento, fazendo-nos todos crer que sua formulação é razoável, aceitável e até partilhável por aqueles que acompanharem o desenvolvimento de sua exposição, mais do que a exibição de um raciocínio raro ou original. $O$ fato é se ele permitiu que 
visualizássemos tal movimento de leitura através da poesia de Murilo Mendes foi porque demonstrou ser possível, por seu turno, a manipulação de um instrumental de leitura para além de sua formação intelectual ou de seu lugar institucional e até de seus princípios ideológicos, de maneira sistemática ou previsível, para se arriscar numa especulação aventurosa e sem garantias de resultados. Assim colocada como algo aventureiro, a leitura adquire outro contorno, menos racional do que sensível, ainda que possamos depurar da sensibilidade algum raciocínio. Por sua vez, tomado como objeto estético, o poema vale mais pelo que pode suscitar enquanto experiência sensível, do que pela ideia que possa carregar consigo, seja rosa, andeja ou migradora, porque adquire feição material no lugar de pronunciamento que o poema vem a ser. Menos do que portador de uma experiência intelectiva, o poema circunscreve um espaço autônomo para o qual todo significado a ser depurado daí haverá de passar necessariamente pela sua consideração de objeto de linguagem singular e autônomo, que permite uma visualização circunstanciada nos termos de sua proposição, o que implica acionar o repertório constituído por leitores outros que se propuseram a fazer o mesmo exercício, que constitui uma prática remota e afirma todos quantos se queiram ver no espelho poemático.

Nesse passo, a expressão literária está radicada num chão em que a comodidade não pode ser natural, nem mineral e tampouco nacional, o que justifica o acionamento de um quadro teórico que não é exclusivo da historiografia brasileira, mas Ihe paira um pouco além, quer pensemos no já mencionado Roman Jakobson, mas também em Jean Cohen com o seu Struture du langage poetique ou mesmo Hugo Friedrich com a sua Die Struktur der modernen Lyric, tal como foram utilizados ao longo do ensaio. Neste seu texto de apreciação da poesia de Murilo Mendes todo o repertório aparece em língua original, o que talvez pareça ocioso em nossos dias, quando os volumes já tiveram larga tradução e edição, a ponto de se tornarem familiares a nosso meio acadêmico, mas não era exatamente assim quando da publicação primeira do "Caderno de análise literária" nos idos dos anos 1980. A despeito disso, é preciso assinalar mais do que um desejo de atualização e de internacionalização das perspectivas de leitura vigentes no Brasil, uma vontade férrea de divulgação literária e de emancipação intelectual, o que talvez pareça desnecessário hoje, mas ainda se colocava imperativamente no ocaso de seus dias de professor universitário. 
Para tanto, quando da incorporação do que fora postulado por Roman Jakobson, se Antonio Candido tivesse se restringido à sua aplicação ao poema de Murilo Mendes, decerto não teria atingido o efeito alcançado pela sua interpretação e o poeta sairia do exercício de leitura como mero exemplário brasileiro, capaz de se subordinar a uma categorização exterior. Ora, isso poderia até servir para quem quisesse divulgar os princípios linguísticos, tal como foram propostos por Roman Jakobson, mas jamais serviria para dimensionar a produção literária de Murilo Mendes, entendida como portadora de uma singularidade expressional, radicada na sua experiência que é moderna e oriunda da sua formação sensível no Brasil, independentemente do idioma falado ou do lugar de publicação, que, no caso, são o português brasileiro e o Rio de Janeiro. Mais do que simplesmente divulgar os pressupostos linguísticos, tal como foram formulados, no que tangencia o eixo da seleção e o da combinação, Antonio Candido se vale de tal postulado para ampliá-lo quando confrontado à poesia de Murilo Mendes, que seleciona pianos entre bois, cavalos e carneiros, produzindo uma combinação que não está prevista no uso comum da linguagem e, por extensão, não poderia ser previsto pela linguística que tenta descrever e conceituar os fenômenos corriqueiros da linguagem, notadamente os de fala, mas que por princípio não deveria se submeter à poesia de Murilo Mendes. Sem inverter os termos da equação, o crítico demonstra como um princípio linguístico de longo alcance pode ser ampliado quando confrontado com uma poesia que ultrapassa fronteiras linguísticas e históricas, porque fortemente amparado na dimensão estética, que vem a lhe constituir de maneira mais fundamental.

Curioso mesmo é que os leitores brasileiros de Roman Jakobson, de uma maneira bem genérica, sempre tomaram os seus princípios para demonstrar como a poesia não era propriedade exclusiva do poema e, quando o fizeram, fizeram de maneira a dignificar algum autor brasileiro pela capacidade de se submeter ao postulado estrangeiro, como se fosse uma espécie de dádiva nacional. De outro modo, aos olhos de Antonio Candido, há um padecimento que é mútuo, tanto do instrumental teórico que expande por meio da particularização poética, quanto do objeto literário que se ilumina na contraluz do instrumento que o revela, circunstancialmente. $O$ resultado imediato mais facialmente identificável é que a obra parece sofrer alguma desestabilização com esse exercício de leitura, assim como o autor passa a ser visualizado por outra angulação e os leitores se veem capazes de interferir no processo de significação da obra, que é dinâmi- 
co e exige constante revisão. Ao final, todos parecem sob outra luminosidade, tanto o autor quanto a obra e, mais ainda, o seu público leitor. Mas dito assim tudo parece meio banal, como parece banal a leitura de Antonio Candido, ainda que se valha da ilustração ou do esclarecimento - como se queira -, tal como tem animado a produção de conhecimento associada à experiência coletiva na tradição ocidental.

\section{Referências}

CANDIDO, Antonio. "Dialética da malandragem" in: O discurso e a cidade. Rio de Janeiro: Ouro sobre o Azul ; São Paulo: Duas Cidades, 2004. p. 17-46

CANDIDO, Antonio.. O estudo analítico do poema. 5a ed. São Paulo: Humanitas, 2006.

CANDIDO, Antonio. Na sala de aula. Rio de Janeiro: Ouro sobre o Azul, 2015.

COHEN, Jean. Structure du langage poétique. Paris: Flammarion, 1966.

FRIEDRICH, Hugo. Die Struktur der Modernen Lyric. Hamburg: Rowohlt, 1956

JAKOBSON, Roman. "Linguística e poética". in: Linguística e comunicação. 8. ed. São Paulo: Cultrix, 1975. p. 118-162.

MENDES, Murilo. Poesia completa e prosa. Rio de Janeiro: Nova Aguilar, 1994 